\title{
Three-dimensional pore pressure prediction in dual phase conditions for slope stability assessment
}

\author{
E.R. De Sousa Pells Sullivan Meynink, Australia \\ M.J. Fowler Pells Sullivan Meynink, Australia \\ G.E. Swarbrick Pells Sullivan Meynink, Australia
}

\begin{abstract}
This paper presents an approach for modelling both liquid and steam pore pressures for prediction of slope stability of proposed mine slopes at the Lihir gold mine in Papua New Guinea.

A three-dimensional FEFLOW model has been developed of the Louise Amphitheatre including a centrally located geothermal zone. The model comprises a detailed lithological representation and some structural zones. The complex interaction of surface infiltration, ocean boundaries, geothermal upflow, dewatering, drainage to existing pits and groundwater and steam relief are represented in the model. The model is calibrated by some 200 vibrating wire piezometers that measure both pressure and temperature.
\end{abstract}

The model predicts both groundwater flow and heat transport for annual pit development. A unique post processing method has been developed to rapidly estimate steam pressures based on the flow and heat predictions. A detailed model assessment process has been developed in order to judge the reliability or otherwise of modelling output.

The output of the process is a three-dimensional pore pressure grid that identifies zones of both liquid and steam pressures. The results can be subsequently viewed or utilised elsewhere, such as inputs for slope stability analyses. Comparison with conventional dual phase modelling using TOUGH 2 is favourable.

Stability analyses are used to confirm slope designs and target locations and times where steam relief is required.

\section{Introduction}

The Lihir gold mine is located on the Niolam Island in Papua New Guinea and has been in operation since 1997. The site lies in the Louise Amphitheatre, which is a collapsed caldera from an extinct volcano and is characterised by intense geothermal activity, elevated rainfall rates and proximity to the sea; conditions which when combined produce elevated pore pressures within the pit slopes.

Due to the geothermal activity present at the mine, pore pressure in the pit slopes can be derived from either liquid or steam pressures, which render conventional groundwater modelling approaches inappropriate for the prediction of pore pressures.

This paper presents an approach for modelling pore pressures derived from liquid and steam phases, allowing for predictions that were subsequently used in slope stability analyses of proposed mine slopes. The following sections describe the approach and modelling conducted at Lihir, results and comparison to a TOUGH2 multi-phase model built for the site.

\section{$2 \quad$ Modelling approach}

The development of a new modelling approach capable of dealing with liquid and steam pressures was required for two reasons. Firstly, the use of standard groundwater modelling codes such as MODFLOW (Harbaugh, 2005) and FEFLOW (Diersch, 2009) are single phase and do not currently provide steam phase predictions. Secondly, the use of multi-phase codes, such as TOUGH2 (Pruess et al., 1999), while able to 
predict pore pressures from the steam phase do not provide the spatial resolution required in pore pressure modelling for slope stability analyses and typically have long running times.

The constraints imposed by groundwater and geothermal modelling codes led to the search for a method that provided high resolution of steam-driven pore pressures and fast running times. The search concluded with a new method using a three dimensional FEFLOW flow and heat transport model for simulation of liquid phase pore pressure and temperature distributions. Once the initial simulation is completed, pore pressure and temperature results are post processed to estimate steam pressures in a process termed the hybrid method, which is illustrated in Figure 1. This process is based on extrapolation of two phase behaviour of a simplified 1D model of groundwater-heat interaction. The 1D model was derived using the multi-phase numerical simulator STOMP, developed by Pacific Northwest Laboratories.

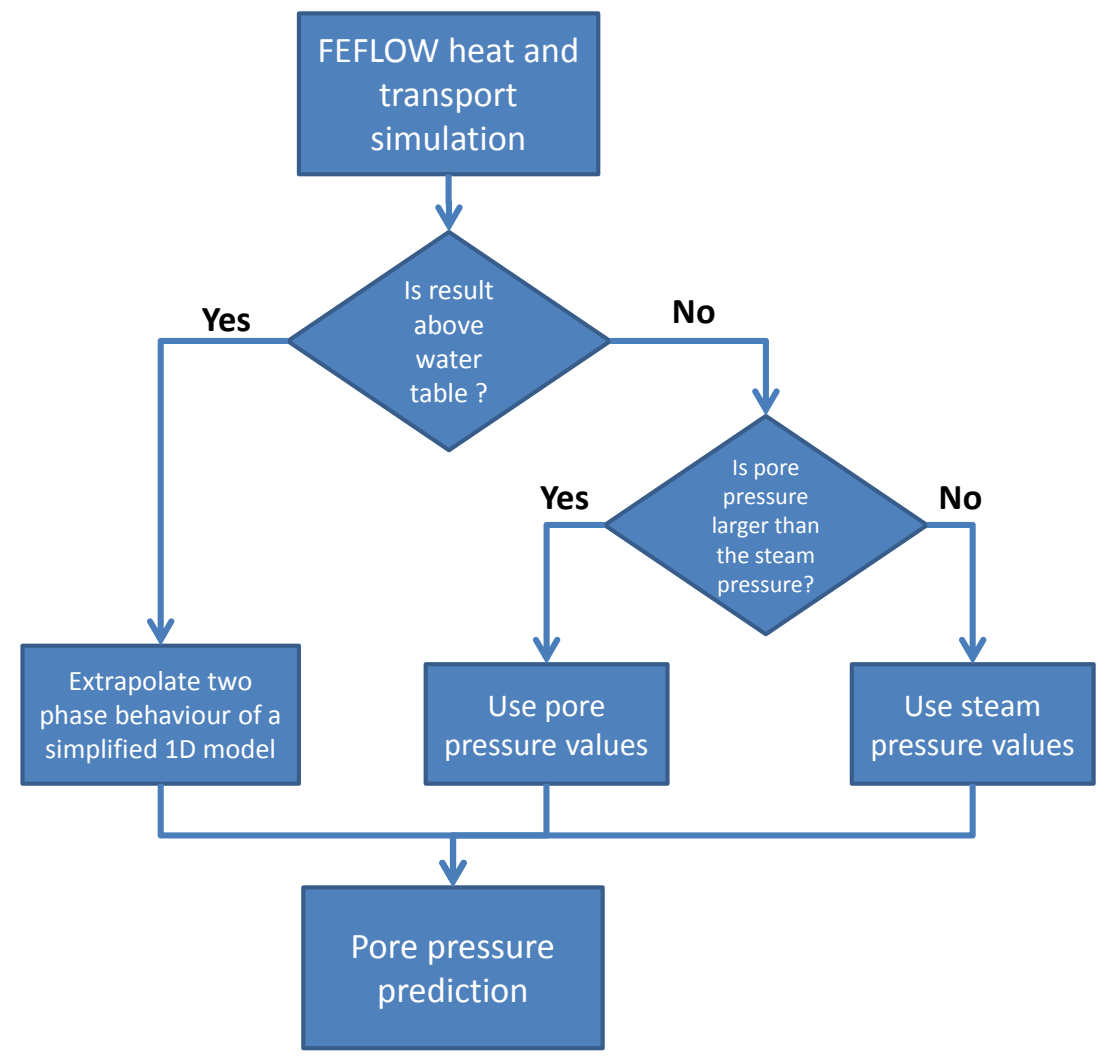

Figure 1 Hybrid method workflow

\section{The Lihir model}

\subsection{Conceptualisation}

Groundwater level measurements undertaken prior to the mining activities indicated a good correlation between topography and groundwater levels. Therefore the groundwater system is assumed to be constrained to the Louise Amphitheatre. Groundwater flow in the catchment is driven by two major sources, namely rainfall recharge and deep geothermal upflow.

In terms of hydrogeological properties, three major zones can be defined in the catchment:

- An upper low permeability unit comprised of argillic oretypes, covering the entire catchment, with the exception of the caldera rims and the landslide area.

- An intermediate unit of high permeability, occurring mostly in the central portions of the catchment and having a significant connection to the sea.

- A lower unit of moderate to low permeability, called Anhydrite Sea. 
Although the area presents a large number of faults and fracture zones generated by a number of different processes, effects of these structures on the hydrogeological regime are largely minimised by alteration which overprints the entire area. One exception however is the Minifie Shear Zone located south of Kapit, where most of the dewatering abstraction currently occurs.

Due to the elevated rainfall rates in the area $(>3,500 \mathrm{~mm} /$ year $)$, recharge is expected be significant even in areas of low permeability.

Deep upflow results from convective groundwater flow and is also a major source of heat. The occurrence of upflow zones is structurally controlled and can be observed through elevated temperatures and surface expressions of geothermal features. Upflow is also observed in boreholes where the total head at the deepest Vibrating Wire Piezometer (VWP) is higher than the head at the shallower VWP, defining upward mass flow gradients.

In areas where upflow occurs, the temperature profile is defined predominantly by the balance between cold water from rainfall recharge and hot water from upflow. Therefore low temperature measurements in VWP's are either associated with shallower depth or areas where rainfall recharge is significant.

The seafloor to the Northeast of the site is a major boundary in terms of hydrogeology. A constant average head of $1,000 \mathrm{mRL}$ (equating to sea level) with some minor variation due to tidal movements is observed along the entire sea floor. Prior to the mining activities, the majority of groundwater heads in the site were above $1,000 \mathrm{mRL}$, making the sea the major mass outflow zone. Furthermore, cold water from the sea also provides a significant outflow zone for heat.

As the pit is excavated, hydraulic gradients are diverted into the pit. The sea, which was originally an outflow zone, now becomes a source of low temperature water to the aquifers. Sea inflow is expected to become particularly high when the pit faces start intercepting higher permeability units known to be present at depth. The inflow of low temperature sea water is also likely to contribute to decrease temperatures.

Pit excavation will generate different depressurisation trends as a result of the different material permeabilities. Depressurisation in areas of low permeability, such as within the argillics, are expected to be slow while areas of higher permeability will promote a faster depressurisation.

\subsection{Model domain and discretisation}

The use of 2D cross-section modelling to provide pore pressure estimates is a common practice in open pit slope stability analysis, since these models are easily implemented and running times are in general small. However, in many circumstances, limitations imposed by this approach render pore pressures estimates inaccurate, if not completely inadequate, as described in De Sousa and Fowler (2013b).

At the Lihir mine geometric and other site specific limitations were found to exist. Consequently, a full three-dimensional model was built with a similar resolution for both vertical and horizontal domains.

In plan, the model domain encompasses the entire catchment within the Louise Amphitheatre and a portion of Louise Harbor. The extent of the plan is based on the assumption that there is no flow across the caldera rim, as stated in the conceptual model (Section 3).

The finite element formulation of FEFLOW makes use of prismatic triangular elements to discretise the model domain. A total of approximately 2.5 million elements were used evenly distributed into 60 layers, with 42,617 elements per layer. Horizontal element size ranged between 20 and $70 \mathrm{~m}$. The model mesh was refined in areas where greater resolution was required, including current pits (Lienetz and Minifie) and the proposed Kapit pit.

Vertically, the top of the model equates to the pre-mining topographical surface, while the base of the model was defined at $500 \mathrm{mRL}$, which is positioned $500 \mathrm{~m}$ below the sea level. The level of 1,000 mRL equates to the mean sea level. The choice of $500 \mathrm{mRL}$ as the base of the model was based on the maximum depth where data from the geology block model was available. 
In terms of temporal discretisation, the model was divided into three domains:

- Pre-mine, where steady-state (equilibrium) was assumed.

- Historical (time-variant), for the period from the commencement of mining until the date of the latest pressure and temperature measurement (calibration period).

- Predictive (time-variant), from which results were generated for the slope stability analyses.

The time stepping of the different stages is defined by FEFLOW's automated time stepping function, where smaller time steps are allocated for periods in which large changes in pressure or temperature are observed. A maximum time step length limit of 30 days was assigned to ensure numerical stability.

\subsection{Parameterisation}

The parameter zones defined in the model were based on oretypes defined at the site. In terms of geometry, the distribution of oretypes is very complex. The adjustment of model layer thicknesses, tops and bottoms, usually provide a reasonable approach for the representation of sedimentary geometries when the parameters zones are continuous. However, difficulties arise in the representation of non-sedimentary geology, especially for models that require high vertical resolution and, therefore, a large number of layers.

A methodology developed by De Sousa (2013) was used to convert the geology block model into FEFLOW parameter zones. This methodology consists of a spatial search for the closest block model cell for each element of the model mesh, retrieving the zone value of that cell. Once the search is finished for all elements, element indexes are segregated according to the assigned parameter zone and selection files $(. \mathrm{xml})$ are created and then imported back into the FEFLOW model. Figure 2 illustrates how the algorithm works.

The final result consisted of 10 parameter zones, one for each oretype and one each for the marine sediments, a pre-existing landslide and the sea. The parameter distribution is quite complex and irregular across the layers, as illustrated in Figure 3.

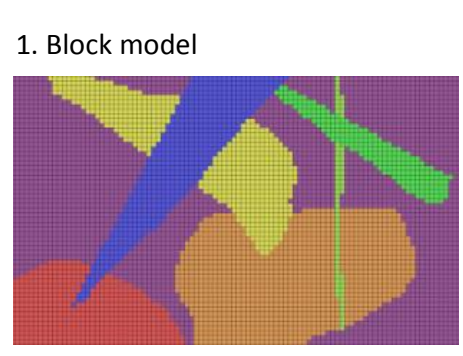

2. Block model and FEFLOW mesh

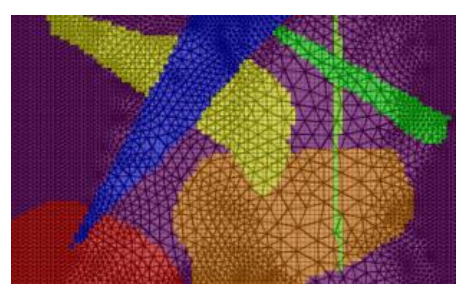

3. Select and element and calculate Distance from block model cells

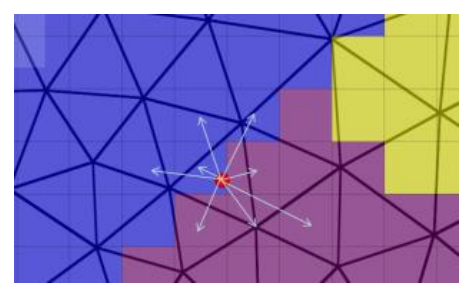

4. Find the closest cell

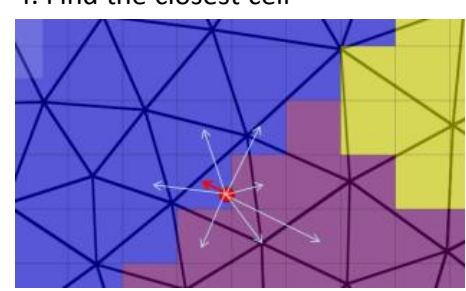

5. Retrieve value from cell and assign to the element

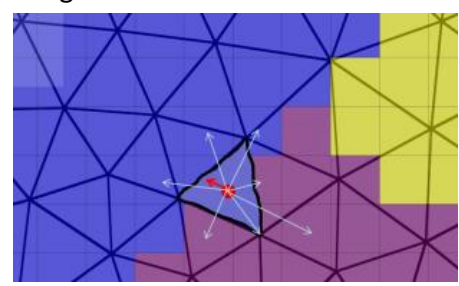

Figure 2 Graphical representation of the methodology used to create parameter zones 

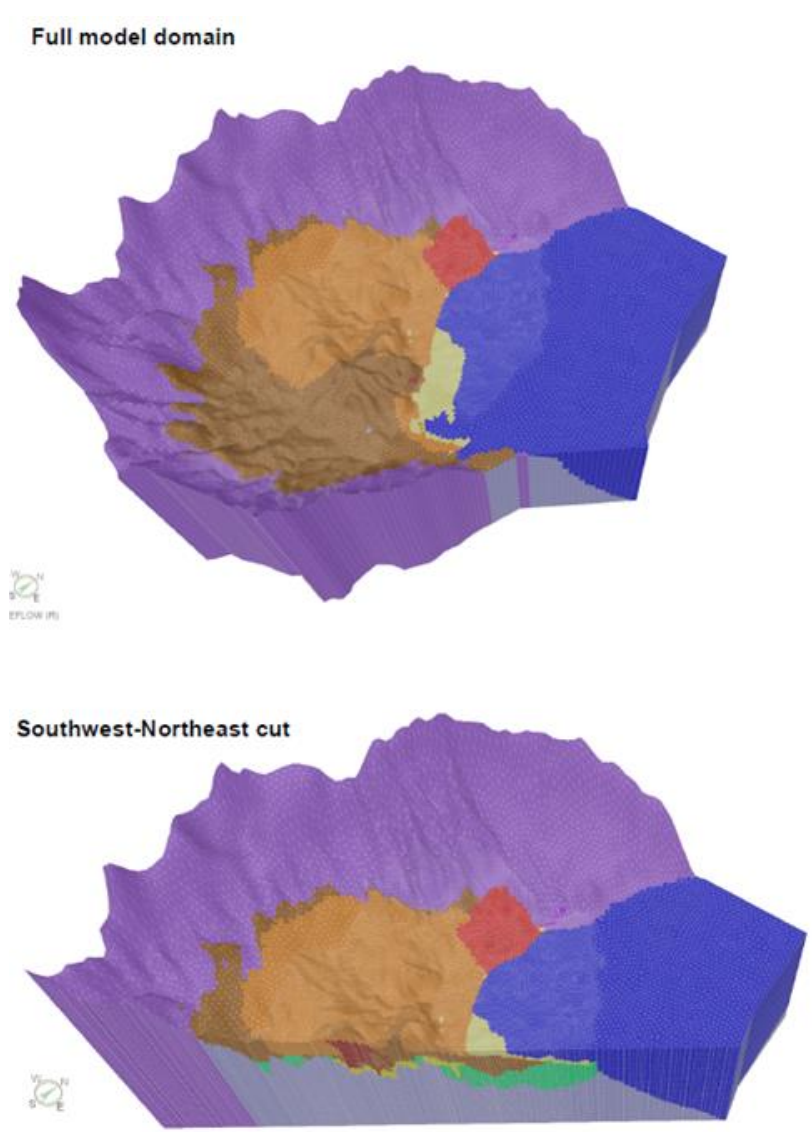
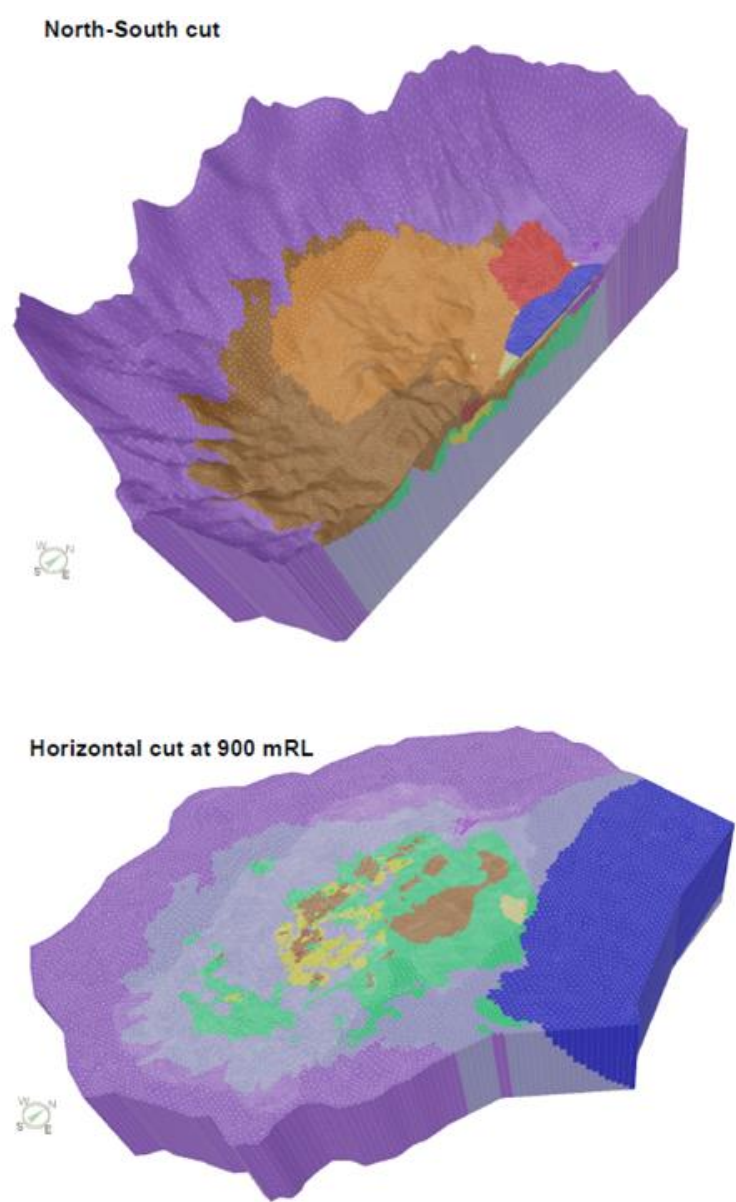

Figure 3 Three-dimensional display of parameter zones generated for the Lihir model

\subsection{Boundary conditions}

Boundary conditions were implemented to represent the heat and mass exchanges between the aquifers and surrounding environments.

In terms of flow boundaries, constant heads were assigned to represent the sea boundary, which acts either as an inflow or outflow zone depending on the hydraulic gradients. Recharge and deep upflow were defined using constant flux boundaries and groundwater abstraction/steam relief was represented using well boundaries.

Heat boundaries were defined as constant temperature boundaries at the surface, to represent heat outflow through the atmosphere, and the base, and to represent heat inflow from the geothermal gradients.

The representation of the pit boundaries was the biggest challenge, given the high complexity of pit development (three pits merging in to one ultimate pit), high vertical resolution of the model and high degree of accuracy required to estimate pore pressures.

A novel method developed by De Sousa and Fowler (2013a) was used to facilitate the implementation of pit boundaries. Monthly and quarterly pit face triangulations were used for the definition of boundaries, with a total of 137 pit layouts.

\subsection{Model calibration}

The calibration consisted of varying the model parameter over likely ranges of values until a satisfactory match between simulated and observed pressure and temperature data was achieved. Data used for the 
model calibration included a dataset of approximately 105,000 measurements of pressure and temperatures distributed over 213 VWPs installed between 2000 and 2012.

The calibration criteria adopted for the model was based on previous studies conducted at the site. These criteria were a compromise between the level of accuracy required by the slope stability analysis, model limitation and uncertainty with regards to parameter values and observation errors.

Steps for calibration criteria included Root Mean Squared (RMS) residuals of $30 \mathrm{~m}$ for total head and $30^{\circ} \mathrm{C}$ for temperature, followed by visual analysis of spatial distribution of residuals, analysis of hydrographs, thermographs, and additional metrics for verification of overpressures along the topographical surface (hydraulic uplifting and residual normalised per depth).

The calibrated model presented an average residual of $1.8 \mathrm{~m}$ and a RMS residual of $29.4 \mathrm{~m}$ for heads. Temperature residuals presented an average of 6.8 and a RMS of $27.5^{\circ} \mathrm{C}$.

\subsection{Model results}

The calibrated model provided yearly three-dimensional distributions of pore pressure and temperature for the entire model domain. Of particular interest were results along five geotechnical sections where 2D slope stability analyses were undertaken. As an additional measure of calibration, pit inflow estimates were generated and compared to values provided from site.

The results reflected the main hydraulic and geothermal stresses imposed by the mining activities. An overall decrease in pore pressure and temperatures is observed as a result from pit seepage and dewatering, together with additional cooling occurring from seawater inflow.

These results were post processed as described in Section 2, allowing estimation of pore pressure derived from steam. An example illustrating the post processing of FEFLOW results is presented in Figure 4.

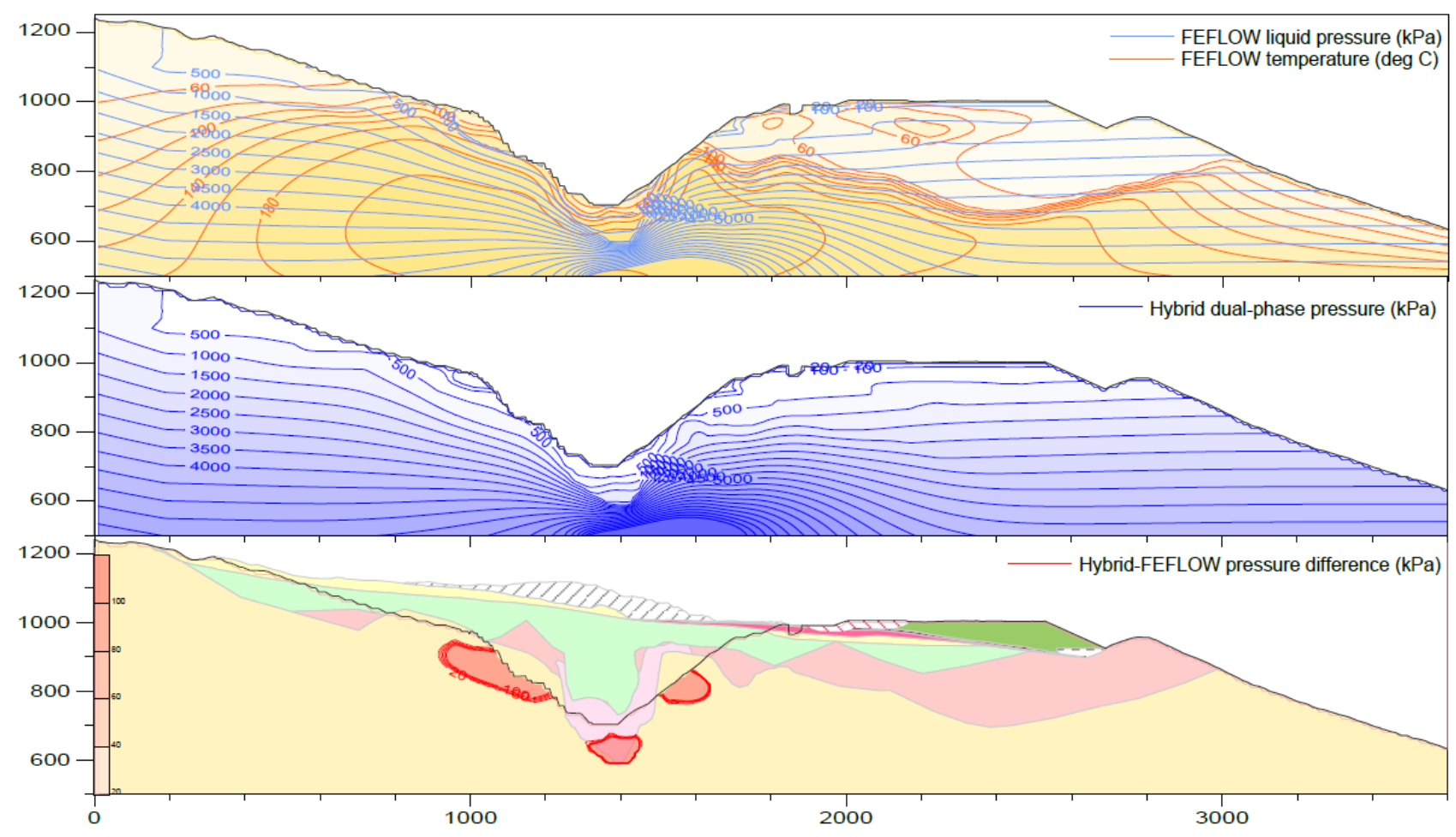

Figure 4 Example of temperature and pore pressure distributions generated by FEFLOW, post processing with the hybrid method for estimating steam pressures, and pore pressure difference 


\subsection{Comparison with TOUGH2 model}

Dual phase modelling using TOUGH2 was undertaken by the University of Auckland in concert with the FEFLOW modelling. The TOUGH2 model covered a substantially larger area with a courser mesh, comprising some 70,000 finite difference nodes with element sizes from 60 to $600 \mathrm{~m}$ laterally and $24 \mathrm{~m}$ vertically. The model was derived from the same block model as the FEFLOW and used similar hydraulic properties.

A detailed comparison of the two approaches was undertaken on key cross-sections as shown in Figure 5. The comparisons were favourable, particularly around the slopes where the pore pressure is most critical.

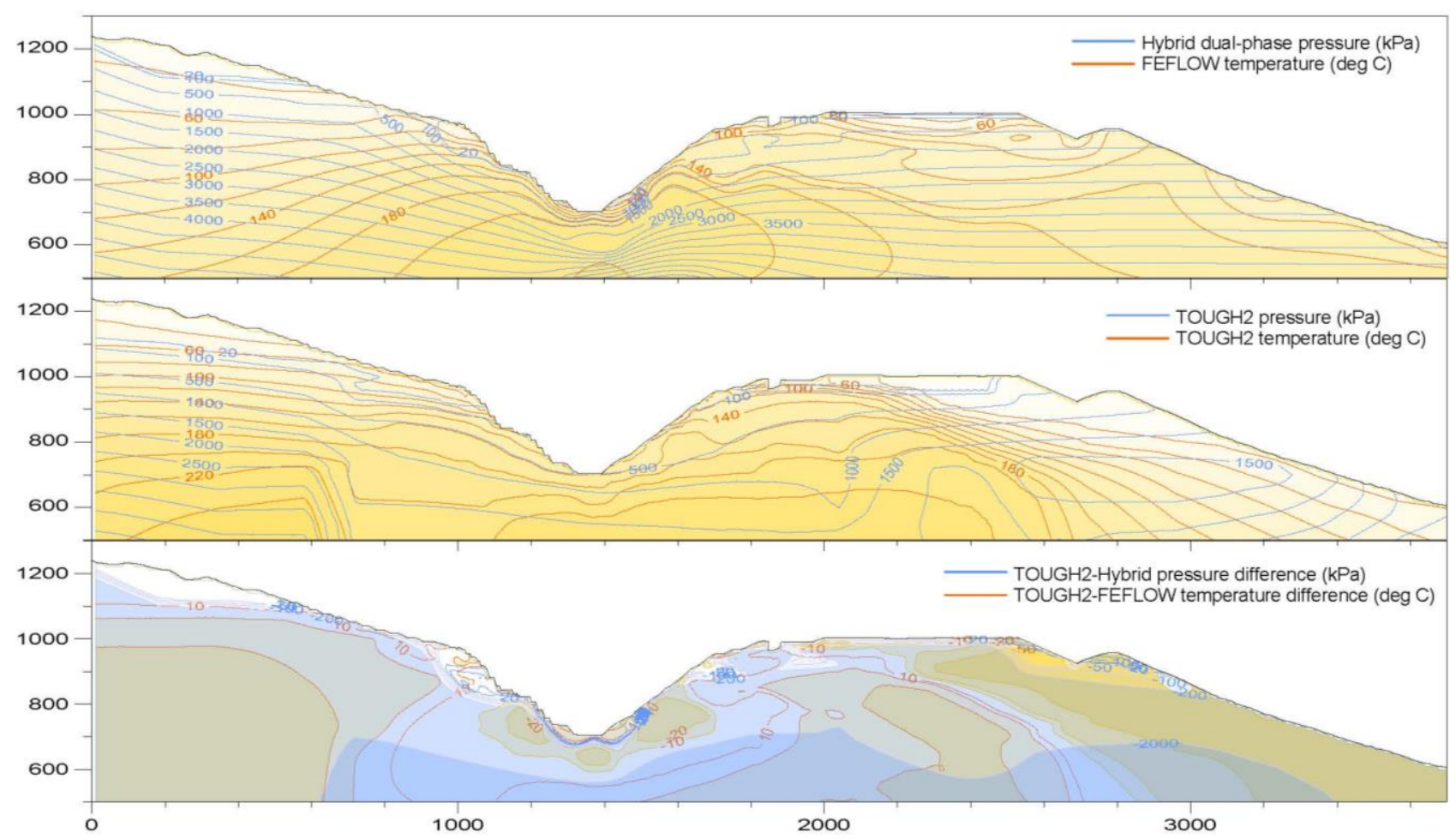

Figure 5 Comparison of FEFLOW and TOUGH2 output

\section{Conclusions}

A new methodology was developed to provide pore pressure predictions in dual phase conditions for slope stability assessment. This new method allows the estimation of pore pressure derived from both liquid and steam phases, while keeping relatively fast running and post-processing time.

The methodology has been successfully applied at Lihir gold mine, where pore pressure predictions for five geotechnical sections were provided with one single three-dimensional model. Comparison of model results against the multi-phase code TOUGH2 and results in general were similar, confirming the validity of this approach.

\section{Acknowledgement}

The authors thank Newcrest Mining Ltd (NML) for permission to publish this paper, colleagues from both NML and the University of Auckland for their collaboration throughout the study and Dr Derek Martin for review of the modelling during its development.

\section{References}

De Sousa, E.R. (2013) When layering is not enough - Converting geology block models into groundwater models, in Proceedings of MODFLOW and More 2013: Translating Science into Practice, 2-5 June 2013, Colorado, USA, Integrated GroundWater Modeling Center. 
De Sousa, E.R. and Fowler, M.J. (2013a) Improving open pit boundary conditions in FEFLOW with IfmOpenPits, in Proceedings 40th International Congress of the IAH, 15-20 September 2013, Perth, Australia, International Association of Hydrogeologists.

De Sousa, E.R. and Fowler, M.J. (2013b) When cross section modelling is not enough - Improving pore pressure modelling with use of full 3D models, in Proceedings 40th International Congress of the IAH, 15-20 September 2013, Perth, Australia, International Association of Hydrogeologists.

Diersch, H-J., G. (2009) FEFLOW - Finite element Subsurface Flow \& Transport Simulation System. Reference Manual, WASY GmbH, Berlin, Germany.

Harbaugh, A.W. (2005) MODFLOW-2005, the U.S. Geological Survey modular ground-water model - the Ground-Water Flow Process: U.S. Geological Survey Techniques and Methods 6-A16.

Pruess, K., Oldenburg, C., Moridis, G. (1999) TOUGH2 User's guide, Version 2.0. Earth Sciences Division, Lawrence Berkeley National Laboratory, Berkeley, US. 